\title{
Poetic prosumption of animation, comic, game and novel in a post-socialist China: A case of a popular video-sharing social media Bilibili as heterotopia (C)Zhen Troy CHEN
}

First Published July 12, 2018

Recommended citation: Chen, Z. T. (2021). Poetic prosumption of animation, comic, game and novel in a post-socialist China: A case of a popular video-sharing social media Bilibili as heterotopia. Journal of Consumer Culture, 21(2), 257277. https://doi.org/10.1177/1469540518787574

\begin{abstract}
Based on the case of Bilibili, a popular Chinese video-sharing social media with a core focus on animation, comic, game and novel, this article examines the transnational prosumption practices of Chinese urban youth who mostly belong to Generation Z. I conduct ethnographic research and in-depth interviews with animation, comic, game and novel fans to investigate the construction of heterotopia on Bilibili through their various practices of tactical prosumption. This article demonstrates that young animation, comic, game and novel fans prosume, socialise and express themselves in a tactical and poetic way within the heterotopia, a place of otherness. Various tactics are employed to challenge and counter control, social norms as well as consumerism. Starting with a critical engagement with Azuma's pessimistic view on animation, comic, game and novel fan culture, the notion of 'database animals', I argue that a neglected, albeit nuanced, poetic and tactical prosumption process is evident on Chinese social media. Being the results of an interdisciplinary study, the findings will be helpful to scholars who are interested in contemporary Chinese studies with a focus on the animation industry, fandom, consumption and social media.
\end{abstract}

Keywords Prosumption, heterotopia, Otaku, youth culture, animation, comic, game and novel, ACGN, tactics, strategy, Bilibili, China, consumerism, participatory culture 


\section{Introduction}

Amid the rich local and transnational texts, articulations and practices mediated through social media in contemporary China, the phenomenon of prosumption in the two-dimensional world (erciyuan/二次元, or the 2-D world, contrary to the three-dimensional world where we live, is a virtual and fictional space) renders a rich site for cultural analysis. The 2-D world, an ecosystem fostered around anime, comic, game, and novel (ACGN), has attracted more than 200 million consumers in China, generating 250 billion RMB in 2016 (Wang, 2016). Chinese urban youth are engaged in watching, reading, curating, playing, discussing and coproducing the originally Japanese, now glocal cultural products on Bilibili, an iconic videosharing social media for ACGN in China, fostering a complex and dynamic participatory culture. While some scholars celebrate the positive side fans' participatory practices (Jenkins, 2006), others criticize the exploitation of digital labour or 'communicative capitalism' in a social media era (Dean, 2010). This article aims to assess social media's role in contemporary China from the vantage point of a unique, evolving cultural environment. It aims to provide insight into the Chinese animation industry through examining the tactical prosumption practices of the Chinese urban youth within Bilibili, a strategically built virtual space.

Developers and owners of Bilibili exploit the power of space, based on histories, institutions, cultural adaptation and technologies to boost consumption for financial gains. They strategically build and co-shape an alternative symbolic space, manipulate consumers' behaviour, and exploits participants' affections, associative moods and dispositions. However, I would argue that these strategies cannot be superimposed onto consumers as some of them transform themselves into tactical prosumers. They employ various tactics to 
resist such control, manipulation and exploitation, making Bilibili what Foucault defined heterotopia, a space of otherness (1986).

However, this is largely neglected by the media and academics alike. For example, traditional fandom studies about Otaku (geeks) see ACGN fans as 'database animals' (Azuma, 2009). Research on the emerging equivalent phenomenon in the Chinese animation industry has been scarce, despite the fact that the industry is gaining policy currency and economic significance in China. China now has 513 million online video users (CNNIC, 2016) and the competition between different platforms is fierce (Hu, 2014). From 2009 onwards, a few animation video-sharing websites with danmaku (弹幕/弾幕 literally bullet curtain/screen, a 'bullet chatting' feature with comments bombarding the screen, see Figure 1) imitated from their Japanese equivalents gained popularity. Bilibili stood out and became the first publicly traded animation-streaming social media at Nasdaq at the time of writing.

Even though production and consumption in Chinese animation industry is getting scholarly attention (see, Liu et al., 2016; Macdonald, 2016), scant research has focused on users' mediated sociality and lived experiences. This article aims to bridge the research gap with more nuanced and updated research on how Chinese youth consume and share ACGN content in creative ways on social media.

The analysis in this article consists of several parts. Following the literature review on the proliferation of ACGN consumption in China, empirical data is collected through qualitative methods, namely online ethnography and in-depth interviews. First, I briefly examine the macro cultural context, illustrating the cultural adaptation, participatory processes and network formation on ACGN social media. I argue that a shift from commodification of 
reality to commodification of virtuality is underway. Secondly, I consider ACGN social media as a valuable ecosystem itself at an intermediate level. I argue that Bilibili as a space becomes a commodity itself for the circulation of both tangible artefacts and intangible commodities and thus the realisation of profits. Thirdly, I describe the strategies by which Bilibili obscures the ideal of a utopian 'sharing' platform it claims to build. By engaging in commercial activities and advertisement placing (it promised its users not to), it compromised this ideal. The construction of a temporal and spatial (virtual) ecosystem generates both opportunities and constraints for its commercial, social and political engagements. Finally, at the micro level, I consider Bilibili as heterotopia for various tactics and counter-strategies to be used by the subjects in challenging the value of a consumer society, authoritative control and censorship as well as hegemonic heterosexuality.

\section{Methods}

This research utilises ethnographic methods and in-depth interviews with registered Bilibili users between 2016 and 2017. In addition, valuable information such as danmaku comments and online discussions were also analysed. For interviews, due to ease of access, I started with university animation clubs since participants are well-matched as they are young urban animation fans. I recruited 20 informants through snowballing, with a balance of gender, aged from 19 to 24 . In-depth interviews were conducted individually or in groups. In addition, I presented significant statements from interviews to elaborate relevant themes identified. Names used are fictional to keep informants' anonymity. 


\section{Literature review and theoretical framework}

Taking a Foucauldian heterotopia perspective, this article argues that young ACGN fans construct their own heterotopia through social media. I also combine de Certeau's account on the 'poetics of everyday life' to investigate the detailed tactics employed by prosumers in a participatory culture. This original synthesis works as an overarching framework to inform my analysis. However, I will first start with a relevant and critical engagement with Azuma's critique on Japanese Otaku (geeks), 'the database animals' (2009) in a Chinese context.

\section{Commodification: from reality, to virtuality and sociality}

Following China's political reform to open up society and the economy from 1978, consumerism has taken root and flourished. In line with Deng Xiaoping's vision, 'let some people get rich first', China has adopted a market economy with Chinese characteristics. That is, the economy has undergone a radical privatisation process while keeping various modes of ownership (e.g., state and private). China has integrated with the world at different levels in the globalisation process (entered WTO in 2001). As the second largest economy measured by Gross Domestic Product, China became the second largest online retail market back in 2013 (MGI, 2013). As mentioned before, online ACGN consumption makes a significant contribution. According to Hulme (2014: xxiv), the Chinese government has launched various 'vigorous' campaigns to encourage spending to achieve a xiaokang (小康 moderately prosperous) society and boost domestic economy. It is an important step for China to be part of the consumer society, a mode of organisation desired by nation states. Many scholars have examined consumer behaviour and identity of Chinese middle class through consumption of commodities and cultural products (see a recent edited volume, Hulme, 2014). Commentators and journalists alike criticize that in China 'everything is up for trade' $(\mathrm{Xu}, 2007)$. The rising consumerism occupies physical places (shopping malls), online retail spaces (ecommerce) 
and now the online social spaces (social media). The commodification of intangible knowledge, desire, affections and emotions underpins this particular case study on Bilibili. In line with the critical scholarship on consumerism, Azuma's 2001 book titled Otaku: Japan's Database Animals was one of the earlier works dealing with ACGN consumption. His critique was widely discussed in the media and among ACGN fans following his 2016 visit to China corresponding the tension between the unprecedented booming of ACGN industries in China and the tightening media regulatory regime $(\mathrm{Wu}, 2016)$.

\section{Otaku culture in Azuma's animalised Japan}

Critique on globalised consumer society and corruptive materialism is not new (e.g., the Frankfurt School). Such critique on Otaku (animation geeks) culture is best known from two major strands of works: Marxist commodity fetishism; and psychoanalysis from a Freudian and/or Lacanian perspective (Yiu and Chan, 2013). Drawing on Kojève and Hegel, Azuma (2009) takes a philosophical perspective and contends that the compulsion toward databasification animalises human beings (Otaku as the extreme) in the postmodern condition under which 'people come to use cultural products for the immediate satisfaction of needs without searching for or desiring profound underlying meaning', thus the diminishing of the desire of others' desires (2009: xvi). That is, in postmodern Japan, grand narratives such as ideology lose appeal, and become replaced by small narratives and eventually by a database or architecture in the form of Baudrillardian simulacra (see Baudrillard, 1994). Azuma (2009) termed this algorithm-based database 'grand non-narrative'. Under such a condition, originality is no longer important. Through producing and consuming simulacra - constituted by moe-elements (moe yosō 萌え要素, character traits) - one cannot distinguish between originals and copies. Therefore, narratives and acting skills are no longer important as long as the moe-elements are there to satisfy consumers' needs and gratification. This is particularly 
the case for ACGN as it relies on 'poker-faced' avatars instead of real human. To be fair, Azuma does not aim to pathologise Otaku through psychoanalysis. However, Chinese media's interpretation distorted Azuma's work as a criticism of the obsessive ACGN consumption, a moral panic that Chinese youth may be turned into an animalised and infantile generation (Gao, 2017).

\section{Chinese ACGN fans' prosumption in a participatory culture}

ACGN fans are broadly defined and thus not monolithic. The focus of this article centres on the registered users of Bilibili, who consume ACGN primarily on social media in China. Compared with who Otaku are, I am more interested in what ACGN fans can do on Bilibili in a participatory culture. Consumers/prosumers of ACGN are first of all fans, while only some are Otaku (geeks). In light of de Certeau's poetics of everyday life, it is the circumstantial practices and relationships that define the terms to denote relationships in everyday life, rather than the other way around (Highmore, 2002). Although I tend to agree with Azuma's more metaphysical critique on consumer society, I argue that users' subjectivity and agency should not be neglected, thus a critique on his critique. That is, fandom should not be conceptualised only as polarised extremes: to either meet animalised (genital) needs or desire of others' desires. The needs, desires, affections and emotions should be analysed as in a continuum and spectrum. In order to do that, I draw on existing literature from participatory fan culture (Jenkins, 2006) and the relevant notion of prosumption.

In our increasingly mediated, globalised and binge-watching world, fans become more like the curatorial consumers who buy, collect and participate in creating relevant artefacts they like (Tankel and Murphy, 1998). Jenkins (2006: I) uses the term 'poachers' to describe fans who use the source text to create new derivative works with new meanings which reflects 
their subjectivity and agency. The mode of prosumption is distinctive from ordinary mass culture consumption as it gives the collector a sense of achievement and create spaces for prosumers to negotiate their desired identities (Flew and Humphreys, 2005). Prosumption as a conflation term refers to both production and consumption (Ritzer and Jurgenson, 2010) as well as value and experience co-creation (Grimes, 2015). The notion of prosumption highlights consumers' subjectivity and agency in a participatory culture (Galuszka, 2015). The term was used to denote the new relationships between creators and fans, avoiding the bipolar term of producer and consumer (van Dijck, 2009). This is particularly evident in the social media age as digital technology affects and weakens the barriers that separate production from consumption (Zajc, 2015). Social media allow prosumers to form places of otherness (heterotopia), which will be explained in detail below.

\section{Foucauldian heterotopia}

Foucault's conceptualisation of heterotopia (1986) focuses on social space consisting of a multiplicity of distinct human 'sites'. He argues that these sites should be investigated as various 'network of relations'. These 'irreducible' sites are not 'superimposable', making the society a 'heterogeneous space' which has a 'curious property of being in relation with all the other sites, but in such a way as to suspect, neutralise, or invert the set of relations that they happen to designate, mirror, or reflect' (24). Heterotopia, constructed as non-hegemonic social sites, are connected with other sites, yet contradict them (Hetherington, 1997). According to Foucault (1986), these spaces of otherness are ubiquitous and can be traced in almost every culture. It presents a different world which is full of hope and potential. In such a space, technologies, disciplines and institutions are out of order or temporarily suspended, allowing change to take place or to make the so-called deviates appear normal so that life could go on (examples used are prisons, hospitals, schools and shopping malls). The 
boundary-challenging space can be conceptual, physical, literary and even imaginative. It provides shelter for a community of otherness to form new relationships, strive and dissolve and is equipped with inclusion and exclusion switches. My interpretation of Foucault's account on the principles of heterotopia primarily focuses on the curious dialectical property in terms of time and space. According to Foucault (1986), neither the linear time nor sanctified space is superimposed in heterotopia. First of all, heterotopia offers opportunities for subjects to manoeuvre in a single real place with the juxtaposition of several incompatible spaces. Secondly, linear, eternal and accumulative time can be suspended and broken into temporal slices of time, such as in museums, vacation villages and festivals. Thirdly, heterotopia is a system switching on and off, thus both exclusive and inclusive (insolating and penetrable, in Foucault's terms). That is, some seemingly open spaces have curious exclusions. In sum, heterotopia is a space of otherness. It can work both as illusory and another real space for compensation as the perfect and meticulous, contrary to the hegemonic time and space. This notion has provided an alternative for some radical leftist and conflict theorists who hold binary oppositional views on socio-political change and class struggle, for example, utopia verses dystopia. Regarded as 'sites' for relationships, heterotopia was coined long before Castells' notion of the networked society (1996). Foucault calls for imagination and subjectivity in the form of heterotopia, whereas in our networked society and on social media, we are already connected or disconnected by exclusions, online and offline with heterotopic endowments at our disposal.

To put it into perspective, I argue that heterotopia can be achieved through the juxtaposition of real life experiences behind the screen and fans' prosumption practices on Bilibili. ACGN fans can have hybrid identities simultaneously in this virtual heterotopia. For example, danmaku on Bilibili creates a quasi real-time virtual space in which users feel they watch 
videos together. The conceptualisation of a Foucauldian heterotopia is useful to outline the struggle and repression faced by today's Chinese urban youth, including but not limited to, 'their singleton status, high parental expectations, the competitive educational and economic systems, the authoritarian political culture, and the lasting influence of a hierarchical tradition that sees young people as juniors in both the family and society' (Liu, 2009: 172). In other words, Chinese Generation Z are still under parental or adult control (or care, depending on the discourses associated with it) and are constrained by the established, sanctified categorisations of spaces, such as home, school, and the society. And the concept of heterotopia aims to desanctify such spaces and manipulate time by creating temporal spaces of otherness, where freedom, flexibility, and hope can be sought after and achieved.

\section{Strategy and tactics in the construction of heterotopia}

In a Chinese context, for some scholars, Chinese youth in the 1950 s to 1970 s were revolutionary and idealistic whereas the globalising capitalism is turning the youth in China into passive masses, losing their subjectivity and agency in the post-revolution era (Dai, 2017). This echoes Lefebvre's critique that the postmodern society is penetrable and controllable by consumerism and the existence of poetry has been evicted (1991). I find this critique problematic as the elitist view simply denies the subjectivity and agency of consumers and prosumers, who can achieve individual and collective intelligence through various tactics. Here, I draw on de Certeau who believed that everyday life is extraordinary and nothing is prosaic but poetic, which means to create, to invent, to generate (Highmore, 2002). This is powered up by the resistance against societal disciplines established within everyday life, through which people operate or make do with the society. The resistance is achieved through two forms of actions: strategy, which denotes the rules and norms established in life; and tactics, used to resist the strategies from within the system (Highmore, 
2002). Strategies are proprietorial, including: place, property, and ownership etc., whereas tactics extend as a war analogy through which people employ 'possibilities within strategic circumstances: disguise, surprise, discretion, secrecy, wit, play, bluff and so on' (ibid, 159). People keep resisting and thus find beauty and meaning in everyday life.

In addition, de Certeau's notion of resistance is not to privilege the oppositional character of everyday life, which differentiates his idea with Lefebvre's view on the politics of everyday life. That would require a counter-strategy for subjects to leave the strategy (taking place in a given space they adhere to) even though they may be resisting it tactically. This resistance is conducted in the operational everyday practices initiated by the subjects who use them with a plural quality as in a continuum. De Certeau offers a new set of languages to guide the investigation of the practice of everyday life which 'escape[s] without leaving' 'the dominant social order' by creating new spaces and temporalities (159). Compared with Foucault, where heterotopia is a 'philosophically doable' condition for subjects to create and maintain new forms of connections and relationships, de Certeau's poetic tactics provide detailed approaches and methods for subjects to 'make do' in their everyday life.

In this article, I aim to provide a synthesis of Foucault and de Certeau's thoughts that the repressed subjects (urban young ACGN fans) use various tactics to question, neutralize and invert time within the spaces of established (or establishing) strategies and thus achieve temporal and spatial guerrilla wins in heterotopia. This is a firm denial of the possibility of a full control by the hegemonic and capitalist logic. This synthesis challenges the traditional socio-political and economic frames, for example, writer and reader, elite and amateur, as well as producer and consumer. Equipped with this synthesis, we can grasp how control and resistance, connection and disconnection, desire and negation, production and consumption 
coexist, providing a new lens to understand how prosumption is practised on a newly established social media, Bilibili.

\section{Commodification strategies: globalisation, shanzhai and culture adaptation}

Bilibili, is a social media platform and fan community offering ACGN contents in the fictional 2-D world. It was created in 2009 by Xu Yi, a dedicated post-1990s ACGN fan (Pandadaily, 2018). As the initial cohort of users on Bilibili have been immersed in Japanese ACGN culture for several years, many fans are proficient in Japanese, tech savvy and culturally aware. Initially a not-for-profit fan community, Bilibili heavily relies on user generated contents (UGC) and user uploaded contents and its popularity extends to offline roadshows and festivals. By the time it held its initial public offering (IPO) at Nasdaq on 28th March 2018, Bilibili disclosed in a report that it has attracted more than 71.8 million monthly active users, $81.7 \%$ of whom are Generation Z, born from 1990 to 2009 (see Bilibili, 2018).

As will show below, Bilibili strategically commodifies users' sociality and desire on social media. This commodification process is also coordinated through a wider cultural adaptation process, as prosumption started long before the social media era. China's animation industry started to develop as early as the 1920 s when meishu (美术 fine art) animation gained global recognition as the Chinese School (MacDonald, 2016). Yet, for a long time, the Chinese market is dominated by Japanese and American Hollywood animations. In the last decade or so, China has followed the discourse of cultural and creative industries with an aim to move its industry up in the value chain, by going out to the world (Chen, 2018). Such encounter is arguably best reflected in the shanzhai (山寨 imitation, prototyping and creation)

phenomenon in Chinese animation industry ${ }^{1}$. To draw on Lotman, such cultural adaptation process normally consists of five stages: strangeness, transformation, abstraction, 
productivity, and transmission (see details, 1990: 144-147). Anime has its distinct Japanese aesthetics which appears strange to the receiving Chinese culture at first. However, transformation starts with 'translating' ideas, 'transforming' the foreign texts, genres, and formats. For example, subtitle groups (zimuzu 字幕组) played an important role in translating and co-producing animations as the earlier generation of prosumers ( $\mathrm{Hu}, 2014)$. Abstraction is the stage where imitation transcends its Japanese origin and forms a higher value as abstract ideas, thus losing its foreignness. Once abstraction is thoroughly completed, the original and even marginal texts start to generate productivity in China. Therefore, shanzhai, when understood critically, is not mere copying. It is a mutual constructing process, a cultural 'transmitter' for the local Chinese culture to break with its past (the Chinese School) and incorporate the foreign, and vice versa. Bilibili is such a recent 'transmitter' - even though the business model is not entirely original, the reviews and derivative works hosted by it are unique in a Lotmanian sense. In addition, this process is boosted by the Chinese government implementing a policy control on imported animation to develop its domestic animation industry (Ishii, 2013).

\section{ACGN fans' negotiated identity on Bilibili}

Otaku share a hybrid name, however, they have local specific characteristics in the Chinese market following the above cultural adaption process. In Japan, Otaku refers to obsessive consumers of anime and manga originally perceived as anti-social or misfits (Azuma, 2009). However, it is more suitable to understand Otaku as ACGN fans in China since the meaning of the term has been expanded through cultural transmission process. For Bilibili informants, they treat Otaku (zhai 宅) as a neutral and even fashionable label and cultural capital to socialise with people. As a 20-year-old organiser of a university animation club, Suyang suggests, 
I am Otaku, however, I am just a fan who enjoys ACGN. I don’t think animation fans think themselves as some few radical Japanese Otaku (死宅 sizhai, deadly Otaku) who end up murdering girls because they watch too many gal-winning animations. I think the meaning of zhai nan/nv 宅男/女 (home-boy/girl) is boarder...We are free to choose to be zhai when we want to stay at home enjoying ourselves.

Suyang's reflection reveals a sense of subjectivity which is widely shared among the informants. The transcultural term Otaku refers to not only a homey state but other spaces as comfort zones where Chinese fans feel a sense control, where they can do things they are good at and feel a sense of belonging/existence (存在感 cunzai gan). Unlike previous generations, Generation $\mathrm{Z}$ have been labelled with stereotypical characteristics such as individualist, rebellious, lonely and apathetic (Liboriussen, 2016). Such labels revel a biased repression from their family and the wider society as they are under great expectation. They were born after 1990, an interesting time as Chinese society underwent dramatic changes after ten years of open-up. Their families constitute the Chinese rising middle class, where Internet access, computer and portable devices are taken for granted in today's urban China as 'an enhanced lifestyle and social mobility' - in sharp contrast to the lack thereof in their parents' lives (Liu, 2009: 169). Urban ACGN fans face intensified pressure, often as the only child in family, to become successful in a fast-changing society, 'characterised by sharp social stratification, fierce competition, lack of security, consumerism, corruption and unfairness in the distribution of resources' (167). Bilibili thus functions as a cultural and signification place for the youth to hang out or escape to, in order to express themselves and explore their identities. 


\section{Strategies: the commodification of Bilibili}

With the Chinese government's crackdown on rampant piracy, video platforms underwent a consolidation process. Bilibili strived and became a prominent cultural transmitter for ACGN communities. A 22-year-old female informant who started to use Bilibili from 2011, Yoshiko, suggests that even though she is amazed by Bilibili as it streams most updated animation series almost simultaneously with Japan, she is more attracted to Bilibili's community feature:

With danmaku, you feel hanging out with millions of people at the same time... I enjoy singing so I started to post covers of songs there...I wanted the attention (which was impossible to get in her then real/offline high school life).

The informant thought she could 'make it' as she already attracted more than 3,000 followers on Baidu Forum before moving onto Bilibili. She experienced a transition period when traditional dispersed platforms started to converge on social media such as Bilibili. Convenient viewing experiences with up-to-date content, enhanced interactivity and welldeveloped global connection, has laid a good foundation for Bilibili to flourish in China. Bilibili was created by fans in a grassroots fashion, a key strategy for the management team to attract users' support. On its official Sina Weibo I follow, Bilibili claimed that it would remain free and never have advertising and commercial placement on its website or above the videos. This gained enormous fan support for it to achieve network effect. In addition to UGC contribution, monetary rewards - Bilibili coins donation and crowdfunding for obtaining and streaming copyrighted animations - play a key role for Bilibili to maintain its popularity (Xiao, 2017). However, as Bilibili gained influence, the monetization and commodification activities started to breach its original promise. Its strategy shifted from positioning itself as a free grassroots community towards a service provider providing better 
services. This shift has irritated many fans, which in turn led to Bilibili issuing an apology letter on its website and its founder's Weibo account, @bishi, in 2016 to justify this change. Fans' petition was dissolved through Bilibili's commodification strategy which obscured users' perception that it is a utopia free from capitalist exploitation. This evidently shows that users' emotions, desires, and sociality are being commodified with rising consumerism in China.

\section{Exclusivity strategies}

Bilibili also builds its own hierarchy through rating system and exclusivity strategies. In doing so, it fosters an exclusive commodified space using gatekeeping and otherness construction despite its earlier marketing strategy to create a friendly and tolerable community. To create and manage a disciplined space, Bilibili develops a set of rules users have to follow from registration. One can visit the site and view most content, however, other exclusive services are only available to registered users. Bilibili has strict control over taking in new members to retain the 'purity' of its community of ACGN fans. To get registered, I had to answer 100 questions covering ACGN knowledge, etiquette regulations and good practice on Bilibili. The 'membership exam' excludes non-ACGN fans who have little knowledge about ACGN or Bilibili. Questions asked require answers that provide detailed information on plots/dialogues, moe-elements (character traits), and even avatar nicknames given by Chinese fans. Such gatekeeping strategies not only specify what contents and comments are allowed and encouraged, but also what behaviour is prohibited and punished. For example, invective, ads placing, and yinzhan (引战) comments (to cause a fight or quarrels $^{2}$ are not allowed. Users can report any content/comment that makes them feel uncomfortable. Once examined and confirmed by the website administrators, offenders will be put into the 'little black room' specifying their wrong doings publicly. Punishment based 
on severity also applies, ranging from upload/comment function suspension to permanent deletion of an account. There is also social pressure towards regulation offenders. Offenders are called 'pupils' (xiaoxuesheng 小学生), with negative connotations such as immature, less educated or couldn't care less about others' feelings. Ironically, this is similar to the retribution individuals encounter as the powerless in their own real lives. Bilibili users internalise and establish power and hierarchy (strategies) in this commodified space. These curious exclusions are evident examples to show how heterotopia is constructed on Bilibili. It appears to be open, at the same time, divisive with boundaries engineered to prevent 'uninvited' users from engaging with this space in meaningful ways. The penetrable yet isolating characteristic of this heterotopia is exemplified in its exclusivity mechanisms membership exams, rules and regulations, as well as punishments - as purification rituals to manipulate and control users' behaviour.

\section{Tactical heterotopia construction}

Bilibili describes itself as 'a full-spectrum online entertainment world' providing 'highquality content and an immersive entertainment experience', and it admits that the platform relies on 'strong emotional connections' of their users to their content and communities (Bilibili, 2018). However, the users have used an enumerative term to call it a zhai, moe and $f u$ community to explorer their hybrid identities which will be explained in detail below. Relevant tactics discussed below render Bilibili a heterotopia at a micro individual level.

\section{Hybrid identities and communities}

Zhai 宅, literally home, is initially a first-person pronoun for Otaku in Japanese. Like the term 'geek', zhai can be understood as being enthusiastic, knowledgeable, and skilful, for 
example, tech-zhai or academic-zhai (see also, 'Aca/fan' in Jenkins, 2006: I; Yin and Chan, 2013). Moe means budding or blooming. It refers to 'desirable or to desire', a feeling of being stimulated emotionally or sexually. According to Azuma (2009, p.42), moe-elements are 'developed to effectively stimulate the moe 萌 of the consumers', most of which 'are visual, but there are other kinds of moe-elements, such as a particular way of speaking, settings, stereotypical plot (narrative), and the specific curves of a figurine'. $F u$ 腐 is derived from fujoshi, rotten girls, who are attracted by the genre Boys' Love (BL, also known as Yaoi). It is similar to the slash culture known in the west that gained market significance and academic attention (see Zhang, 2016). The meaning of $f u$ gets expanded to cover genres that explore non-heterosexual or homoerotic relationship between characters, such as BL, GL (Girls' Love), and agender characters. Therefore, users identify Bilibili as 'the largest same-sex social media' in a humorous and self-mocking way, which repetitively appears in danmaku. This has a twofold meaning: firstly, works of this genre on Bilibili group people with the same sex in general, for example, girl winning games/animations for male users, while BL is primarily created by and for female users; secondly, such works explore alternative values that challenges the strategies within the society such as heterosexual hegemony (SugawaShimada, 2011). These three features differentiate Bilibili from other social media and users' real lives as an alternative and 'othered' space.

As explained by one male informant, Shenshi: in the virtual 2-D world people at his age who have girlfriends in real life are called xianchong (リア充), an abbreviation referring to people who live a fulfilling and substantial life. In some animation, if characters develop a romantic relationship, the screen will be bombarded with playful danmaku comments, such as xianchong baozha (get exploded), or xianchong qusi (go to hell). He is a dedicated fan of the hougong (harem) genre. Hougong literally means back palace, a harem of a monarch. This 
genre explores romantic (sometimes erotic) relationships between one male character and multiple female characters with various moe-elements. As for his female counterparts, the rotten girls (fujoshi) are rather obsessed with BL genres, exploring romantic and erotic relationship between two bishonian (beautiful boys). Fans will watch various anime series with similar themes for multiple times. Informants do not deny their pursuit of pleasure and gratification, while some emphasized other social and emotional reasons. As BroCheng, noted:

The reason why I watch the show so many times is because it is cathartic, especially when I have pressure... When I watch a show, or play a game, I feel the control of power and happiness... In this loving and friendly site, you are never alone. You can always see how many people are watching together with you at ease.

When I asked why he did not, instead, talk to his friends about such feelings and pressures, he replied:

Girls would talk to their friends about that. I don't want to show my weakness; it is not what men are supposed to do... it takes time to find a person to share your emotions without concerns (of being judged). On Bilibili, friends (fans) are always so nice.

We can sense the loneliness, self-pity and identity struggles among Chinese urban youth as revealed above. However, Bilibili provides a social heterotopic space for Otaku to express themselves and dissolve pressure as they find it difficult to share 'the self' with friends faceto-face in real life. Culturally constructed constraints and strategies, such as masculinity and non-heterosexuality, hinder the free expression of feeling and emotion. By contrast, fans can explore their hybrid personalities on Bilibili, 'a friendly community full of love, understanding and tolerance'. To these informants, the tactical practices in this heterotopia include, escapism, disguise (anonymity) and even the simple expression of true feelings. 
These tactics are enabled through the manipulation of time and space on Bilibili to work as a resistance to the existing strategies and social norms in real life. It is the repetition and familiarity associated with the embodied labour (watching, commenting, re-creating and sharing) that creates social bonds and a particular aesthetic through long-time media use and immersion. In addition, BL derivative works distort and challenge the original storyline (heterosexual dominance) by 'coupling' two male characters. Therefore, prosumers consume and co-produce entertainment content to gain pleasure, foster community and resist social conventions. Jinlai, who became a 'rotten girl' six years ago provides a nuanced view that is not uncommon among other informants in which she rallies against the presumed gratification-oriented and escapism consumption of BL:

I am not escaping from anything. If I am, I am escaping from the rubbish dramas and novels! Yanqingju (love stories) suck as they always use the old stupid format and plots. A brainless drama queen and a tolerant, rich, handsome man, or maybe two. I am tired of rubbish GBL (girl-boy love). They are challenging our IQ. I'd rather watch BL as two male characters get to know and love each other as two equals. Gender is not an issue, I mean, they could be agender...they love each other against the will of the whole world. The love itself is precious and pure.

Jinlai's view challenges the conventional plot and narrative design in accordance with wider social norms where non-heterosexuality and the open discussion of sexuality are social taboo. This shows she consumes media content in an active and critical way. She adds that she tries not to be judgmental about others' tastes and preferences. She adds: 'Some rotten girls only watch H-BL (BL porn). I guess people will watch diffident programmes with different preferences'. Echoing other informants' views, her comment reveals a somewhat progressive, albeit liberal ethos, given the fact that it is rare for people in China to discuss sexuality, not to mention the rarity of open tolerance for hybrid identities. Bilibili works as one of the very 
few civic spaces where such topics and works can be created, disseminated, and discussed. In this heterotopia, users not only consume and prosume but also get to know themselves through self-reflection and interactions with other users. Her depiction of Bilibili also reflects one key principle of heterotopia. That is, by romanticizing the rebellious love affairs in BL/GL, users create a space of otherness by only altering the gender of one counterpart within a relationship, a tactical 'escape without leaving' the conformity of love affairs in a de Certeauian sense.

\section{A space for active prosumption: fan productivity and mobilisation}

In addition to active and binge consumption, prosumers on Bilibili also produce derivative works, such as mash-up videos, fanzines and light novels. Bilibili also tries to nurture an 'original creation culture' (respect for copyright). This is ambivalent compared with its founding strategy, which is largely based on imitation and shanzhai. As the site develops, it starts to call for copyright protection and even set up a 'Made in China' section (guochuang $q u)$ to boost domestic creativity and innovation (Xiao, 2017). Wobushixiaowanzi, a 20-yearold female informant, has published two novels so far:

I was inspired by EVA (an influential animation) ... I found a lot [of] philosophical references...What struck me most was the socially impotent protagonist who fought a long battle with himself, his father, and his friends. It's about knowing yourself...In the final episode, the show abandoned the philosophical and returned to everyday life settings to depict a totally different ending. That's where my creation began.

She has published two books based on the romance of two male characters and sold around 200 copies. As a new creator she is very proud of this figure in the underground market (BL novels have been censored recently in China). The informant's experience is just one of many 
examples where online heterotopia nurtures non-conventional prosumption in the underground market, challenging dominate market regulations, censorship and the wider social conventions.

Another female informant who leads an animation club talks about her experience as a prosumer, mobilising her prosumption between online and offline through partaking in animation festivals in Hangzhou and cult tourism (seichi junre 聖地巡礼) in Japan. She DIYed costumes for cosplay, shoot and uploaded animation tourism videos and got many Bilibili coins. Bilibili (2018) celebrates such UGC as 'creative professional' works, thus PUGC, which is the life-blood of the community. Despite being asked in July 2017 to take down many overseas animations as a result of copyright violations, it did not affect Bilibili much as $70 \%$ of the traffic are driven by UGC (Xiao, 2017). However, it has to be noted that these cases also reflect the commodification of fans' affective, emotional and creative labour. The next section will investigate the tactics that counter such commodification strategies.

\section{A space for the renegades: baipiao (freeride)}

Fans on Bilibili have developed an ambivalent tactic towards the exploitation of fan labour. Baipiao 白嫖, literally 'receiving sexual service without paying', refers to freeriding in media consumption. Sophia, a female informant explained that it basically means they consume copyrighted works and UGC without paying:

For really good and hard-to-get works, I will pay. But for entertainment and general surfing, I will not. It depends on the quality really. We don't really like officially produced trash that targets our money. We do respect and support original creation (yuanchuang), though. 
The informant reveals a seemingly contradictory message that users are rebellious in the sense that they are against the established corporations which produce market-oriented 'trash', but choose to reward UGC (often created by grassroots), by giving Bilibili coins to them. Fans can also buy (commission) licensed anime series for Bilibili from aboard through crowdfunding. Freeriding as a tactic is successful in the sense that Bilibili still hasn't found a viable business model to support itself (Xiao, 2017).

\section{Tucao as tactics}

As previously discussed, Chinese urban youth find companionship, support and sympathy in this heterotopia as a counterbalance to their repressed status at home, at school and within the wider society. They are trained, by parents and society, to be obedient, to become 'good' children. Competition between Chinese urban youth often gets reduced to academic performance at school. If they do not perform well at school, they become ordinary people and even losers. One of their common tactics is to tucao 吐槽, to vent out anger and discontents through humour, sarcasm, and satire. It is reflected not only through online comments with wordplay but also numerous user-generated tucao talk shows (Hsiao, 2015).

On Bilibili, tucao is combined with memes referencing ACGN content, which constitutes a series coded-language to foster a vernacular culture which can sometimes bypass technical censorship. However, as warned by Rofel (2007), similar to the genre of 'speaking bitterness' or 'scar literature' at the crossroad between the Culture Revolution and economic open-up reform, tucao in the post-socialist China are not meant to be rebellious. In many ways, it works as a subtle critique carrying a snobbish label to demonstrate that the prosumers are better, cooler and more culturally aware. It is a tactic used by prosumers as part of a shared identity within the heterotopia to distinguish with other passive consumers who only consume. Prosumers tucao tactically without leaving the space where they are controlled by 
various strategies and socio-political norms. In so doing, ACGN fans also use tucao as evidence to show they are not fooled by the animation they consume. They not only consume to satisfy needs and desires, but also to criticise, evaluate and recreate media content in a rational and poetic way.

\section{Organised actions and counter-strategy}

Even though scholars have concerns about the over-celebration of participatory culture (see, Gray, Sandvoss and Harrington, 2017), there are cases where the social media has become a quasi-public sphere for political debates in China (Shao and Wang, 2017). As argued by Azuma, the dominant focal points of the animalised Otaku are needs and gratification. Once Otaku's needs are sated, they become animalised and no longer negate nature to find in-depth meaning. Therefore, it seems difficult for the 'animal' to be developed into the political. It needs more motivations or urgency to change the status quo to achieve a counter-strategy in a de Certeauian sense. However, some cases on Bilibili show that the debates and organised events can be politically oriented and socially progressive. Chen (2014) examined a fanorganised debate on Bilibili to demonstrate that prosumers use parodies and other tactics to discuss issues other than entertainment, for example, copyright protection and antiplagiarism.

One informant discussed another relevant case which also demonstrates that prosumers use tactics and counter-strategy to explore serious topics such as homophobia and sexuality. Yuri!!! on Ice is a top-ranked animation within the ACGN community in 2016 (Ristola, 2017). It was available on Bilibili for a short time and later became inaccessible as a result of the pay wall set up by Youku, the exclusive copyright licensee in China. It claimed to be an anime of sports genre, but with strong BL tendency. Some 'rotten girls' and pro-LGBT rights 
fans treated it as a serious work to discuss real life gender politics in figure skating using fictional characters. Compared with the situation on Bilibili, which treated a BL scenario as acceptable and exciting, derogatory comments on Youku labelled the homoerotic plots of two male characters 'disgusting'. The discrepancy in treatments caused language battles (mazhan) on Youku between Youku and Bilibili users (the latter call themselves 'refugees from Bilibili' as the show is not available there). These refugees criticised the quality (suzhi) and manner of Youku users, registering disappointment with the intolerant atmosphere of Youku. The counter-strategy, as one informant told me, is to abandon the Youku service (leaving the dispute). The discussions on social media went beyond the consumption/reception of the animation. Sophisticated discussions covered gender politics, producer and fan identity, as well as political correctness in the 2-D world. ${ }^{3}$ Such progressive discussions, investigations and critiques all contribute to the construction of a heterotopia by prosumers in a tactical and poetic way.

\section{Conclusion}

This article analyses the prosumption practices on ACGN social media Bilibili. The tactical and poetic prosumption demonstrates how prosumers explore and retain their subjectivity and agency in constructing an alternative virtual heterotopia to resist pressure, repression and control in a post-socialist China. The analysis of the prosumption here is broadly defined to have included translation, reviews, curation, derivative works (fanzines, mash-ups, reaction videos, and cult tourism), and cosplay, just to name a few. Content consumption and cocreation are coordinated in a dynamic cultural adaptation process. Some prosumers have stood out by, for example, becoming light novel writers and video producers, blurring the boundary between amateur and professional. ACGN fans prosume content on Bilibili, deeply engaging with the details of the media text as poachers. A big proportion of prosumption is 
associated with desire, needs and affections associated with moe-elements. However, this article depicts a more nuanced picture of the active prosumption of ACGN content.

Prosumers actively engage with debates on gender politics, copyright, among other wider political, economic and social issues through prosumption. These subtle yet tactical critiques, self-expressions and identity explorations are in line with the identity and subjectivity of prosumers, making prosumption a poetic process. Prosumption on Bilibili makes this particular social media a virtual heterotopia in the sense that it mirrors the real world but with more tolerant, friendly, and progressive possibilities.

\section{References}

Azuma H. (2009) Otaku: Japan's database animals translated by Jonathan E. Abel and Shion Kono, Minneapolis: University of Minnesota Press.

Baudrillard J. (1994) Simulacra and simulation, Ann Arbor, MI: University of Michigan Press.

Bilibili. (2018) Company profile. Available at:

http://ir.bilibili.com/phoenix.zhtml?c=254699\&p=irol-homeprofile. Accessed 6 April, 2018.

Castells, M. (1996) Rise of the network Society. Oxford: Blackwell.

Chen Z.T. (2018) "Policy, locality and networks in a cultural and creative countryside: The case of Jingdezhen, China" In Susan Luckman and Nicola Thomas (eds) Craft Economies: Cultural Economies of the Handmade. London, UK: Bloomsbury Academic, 150-161.

Chen X-Y. (2014) Study of youth subculture of network community barrage discourse construction - the Bilibili network on Keyki incident response as an example. Computer Knowledge and Technology 10: 4667-4721.

CNNIC. (2016) Statistical report on internet development in China. Available at: http://www.cnnic.net.cn/gywm/xwzx/rdxw/2016/201608/W020160803204144417902 .pdf. Accessed 3 April 2017.

Dai J. (2017) The spectres of post-revolution. Available at: http://tiny-url.org/dai. Accessed 3 April 2017.

Dean J. (2010) Blog Theory: Feedback and Capture in the Circuits of Drive. Cambridge: Polity.

Flew T and Humphreys S. (2005) "Games: Technology, Industry, Culture" in Terry Flew, New Media: an introduction (second edition), South Melbourne: Oxford University Press, 101-114.

Foucault M. (1986) Of other spaces. Diacritics 16: 22-27.

Galuszka P. (2015) New economy of fandom. Popular Music and Society 38: 25-43.

Gao L.M. (2017) The continuum of infertile: A 2-D world reluctnat to grow up, South Weekly. Available at: http://www.infzm.com/content/125425. Accessed 4 November 2017. 
MGI. (2013) China's e-tail revolution: Online shopping as a catalyst for growth. McKinsey Global Institute. Available at: www.mckinsey.com/.../China e.../MGI_China_etailing_Full_report. Accessed 4 September 2017.

Gray J, Sandvoss C and Harrington C.L. (2017) Fandom: Identities and communities in a mediated world. (2nd edition). NY: NYU Press.

Grimes SM. (2015) Playing by the market rules: Promotional priorities and commercialization in children's virtual worlds. Journal of Consumer Culture 15: 110134.

Hetherington K. (1997) The badlands of modernity: Heterotopia and social ordering, London; New York: Routledge.

Highmore B. (2002) Michel de Certeau's Poetics of Everyday Life. In: Highmore B (ed) Everyday life and cultural theory: an introduction. London: Routledge, 145.

Hulme, A. (2014) The Changing Landscape of China's Consumerism, Oxford, UK: Chandos Publishing.

Hsiao CH. (2015) The verbal art of tucao and face-threatening acts in danmu screening. Chinese Language and Discourse 6: 109-132.

Hu K. (2014) Competition and collaboration: Chinese video websites, subtitle groups, state regulation and market. International Journal of Cultural Studies 17: 437-451.

Ishii K. (2013) Nationalism and preferences for domestic and foreign animation programmes in China. International Communication Gazette 75: 225-245.

Jenkins H. (2006) Fans, bloggers, and gamers: Exploring participatory culture, New York: New York University Press.

Keane M and Zhao EJ. (2012) Renegades on the frontier of innovation: The shanzhai grassroots communities of Shenzhen in China's creative economy. Eurasian Geography and Economics 53: 216-230.

Lefebvre H. (1991) The production of space, Oxford: Blackwell.

Liboriussen B. (2016) Balinghou and Qilinghou Generational Difference and Creativity in China. In: Keane M (ed) Handbook of Cultural and Creative Industries in China. Cheltenham: Edward Elgar, 64-79.

Liu F. (2009) It is not merely about life on the screen: Urban Chinese youth and the Internet café. Journal of Youth Studies 12: 167-184.

Liu L, Suh A and Wagner C. (2016) Watching online videos interactively: The impact of media capabilities in Chinese Danmaku video sites. Chinese Journal of Communication 9: 283-303.

Lotman, Y. (1990) Universe of the mind: A semiotic theory of culture. London: I.B.Tauris. MacDonald S. (2016) Animation in China: History, aesthetics, media, New York: Routledge. Pandadaily. (2018) Bilibili to IPO in US for \$400M, 83 Percent of Revenue From Games. Available at: https://pandaily.com/bilibili-ipo-us-400m-83-percent-revenue-games/. Accessed 6 April, 2018.

Ristola J. (2017) A roundtable on Yuri!!! on Ice (Part1). Animation Studies 2.0. Available at: https://blog.animationstudies.org/?p=1759. Accessed 3 April 2017.

Ritzer G and Jurgenson N. (2010) Production, consumption, prosumption: The nature of capitalism in the age of the digital "prosumer". Journal of Consumer Culture 10: 1336.

Rofel L. (2007) Desiring China: experiments in neoliberalism, sexuality, and public culture, Durham; London: Duke University Press.

Shao P and Wang Y. (2017) How does social media change Chinese political culture? The formation of fragmentized public sphere. Telematics and Informatics 34: 694-704. 
Sugawa-Shimada A. (2011) Rebel with causes and laughter for relief: 'Essay manga' of Tenten Hosokawa and Rieko Saibara, and Japanese female readership. Journal of Graphic Novels and Comics 2: 169-185.

Tankel JD and Murphy K. (1998) Collecting comic books: A study of the fan and curatorial consumption. In: Harris C and Alexander A (eds) Theorizing fandom: fans, subculture and identity. Cresskill N.J.: Hampton Press, 66-69.

van Dijck J. (2009) Users like you? Theorizing agency in user-generated content. Media Culture \& Society 31: 41-60.

Wang Y. (2016) China is obsessed with Japanese anime, and investors are paying attention. Forbes Asia. Available at: https://www.forbes.com/sites/ywang/2016/05/25/china-isobsessed-with-japanese-anime-and-investors-are-paying-attention-2/\#3c5341f52947. Accessed 3 April 2017.

Wu Q. (2016) Exclusive interview with philosopher Hiroki Azuma: democracy being manipulated by the 'public unconsciousness'? The Paper. Available at: http://www.thepaper.cn/newsDetail forward 1567391. Accessed 3 April 2017.

Xiao E. (2017) Amid crackdown on foreign shows, China's youth flock to Bilibili with their own content. TECHINASIA. Available at: https://www.techinasia.com/bilibiliprofile. Accessed 4 Nov 2017.

Xu, Z. (2007) Everything is up for trade (G. R. Barmé, Trans.). China Heritage Quarterly. Available at:

http://www.chinaheritagequarterly.org/articles.php?searchterm $=018$ tradingheritage.i nc\&issue $=018$. Accessed 4 September 2017.

Yiu W-H and Chan AC-S. (2013) "Kawaii" and "Moe" - Gazes, geeks (Otaku), and glocalization of beautiful girls (bi shōjo) in Hong Kong youth culture. Positions: East Asia Cultures Critique 21: 853-884.

Zajc M. (2015) Social media, prosumption, and dispositives: New mechanisms of the construction of subjectivity. Journal of Consumer Culture 15: 28-47.

Zhang C. (2016) Loving boys twice as much: Chinese women's paradoxical fandom of "Boys' Love" fiction. Women's Studies in Communication 39: 249-267.

\section{Notes}

\footnotetext{
${ }^{1}$ Shanzhai 山寨, literally 'mountain bandits', is a place for the renegades to hide in deep mountains. The term is closely linked to the hacker culture with a positive connotation, referring to the fast and efficient prototyping of new business models with localised features which quickly achieves scale effects, blurring the boundaries between the original and the copycat (Keane and Zhao, 2012).

2 This is specifically listed as offensive by Bilibili since comments as such are judgmental of users' taste and preference which is against Bilibili's 'political correctness'.

${ }^{3}$ Bilibili hosts more than 2000 videos exploring topics such as plagiarism and homophobia based on search results.
} 